PII: S0305-750X(02)00023-2

\title{
The Impact of Environmental Regulations on Exports: Case Study Results from Cyprus, Jordan, Morocco, Syria, Tunisia, and Turkey
}

\author{
BRUCE A. LARSON \\ University of Connecticut, Storrs, Connecticut, USA \\ ERI NICOLAIDES \\ The Cyprus Development Bank, Nicosia, Cyprus
}

BASHIR AL ZU'BI

University of Jordan, Amman, Jordan

NABIL SUKKAR

Syrian Consulting Bureau, Damascus, Syria

KARIM LARAKI

Klonic Consult, Rabat, Morocco

MOHAMED SALAH MATOUSSI

University of Tunisia, Tunis, Tunisia

KATALIN ZAIM

Bilkent University, Ankara, Turkey

and

\section{CAROL CHOUCHANI *}

United Nations Economic and Social Commission for Western Asia, Beirut, Lebanon

\footnotetext{
* The analysis in this paper was initiated as part of the MedPolicies Project implemented by the Harvard Institute for International Development with funding from the World Bank as part of the METAP Project. The authors thank the additional members of their case study teams, Rania Khaddovr, Nader Kabbani, and the METAP National Focal Point Coordinators in their
}

countries. The authors also thank the journal reviewers and the editor for helpful guidance in the completion of this paper, and Theo Panayotou, Jordan Kimball, and Sherif Arif for continued guidance and support during the completion of the original project. Final revision accepted: 30 January 2002. 


\begin{abstract}
Summary. - Concern about the effects of environmental policies on trade competitiveness continues to grow in the non-EU Mediterranean regions (e.g., North Africa, the Middle East, Turkey, Cyprus). While the impact of environmental regulations on exports is widely discussed in the region, there has been little empirical analysis of how more stringent environmental regulations might affect exports of key sectors in the future. This paper summarizes the results of six case studies that estimate the impact of potential changes in environmental regulations on exports from a key sector in each country. These case studies, which are based on a theoretically consistent yet empirically tractable modeling approach, suggest that a range of outcomes is likely and depends on a fairly small set of specific information. For some of the cases, expected regulatory changes would probably have little impact on exports, while in other cases the impacts could be substantially larger. In some countries, the range of potential outcomes is largely due to the magnitude of the policy change, the importance of various inputs in production, and the lack of information on international market conditions. (c) 2002 Elsevier Science Ltd. All rights reserved.
\end{abstract}

Key words — trade and environment, environmental regulations, exports, competition, non-EU Mediterranean, Cyprus

\section{INTRODUCTION}

Concern about the effects of environmental policies on exports continues to grow in the non-European Union (EU) Mediterranean regions (e.g., North Africa, the Middle East, Turkey, Cyprus) as "partnership" agreements with the EU are negotiated and completed. The Arab League held meetings on the topic in Cairo, Egypt during September 1999, while the United National Economic and Social Commission for West Asia (ESCWA) held meetings on the topic in November 1999 in Beirut, Lebanon. It is not uncommon for "trade and environment" committees to exist at the national level (e.g., in Egypt) and for members of environmental authorities to assign staff to be responsible for "trade and environment" (e.g., in Lebanon, Tunisia, Egypt, and Morocco). While the potential importance of the basic issue has become well accepted in the region, the "Expert Group Meeting on Environment and Trade Issues" organized by the United Nations Economic and Social Commission for Western Asia concluded that there remains a lack of capacity in these countries to evaluate the likely impacts of more stringent environmental regulations on trade in the region (UNESCWA, 1999, p. 12).

To assist with these capacity building needs, the MedPolicies Initiative of the Mediterranean Environmental Technical Assistance Project (METAP) supported the completion of case studies that analyzed how changes in environmental regulations (actual and proposed) might affect exports of specific sectors of the economy in Cyprus, Jordan, Morocco, Syria, Tunisia, and Turkey. ${ }^{1}$ Edited working paper versions of the case studies can be found in HIID (2000), with the drafts for Cyprus, Jordan,
Syria, and Turkey available in English and the drafts for Morocco and Tunisia available in French.

Given that the case study reports include substantial amounts of additional countryspecific detail, the primary purpose of this paper is to explain and synthesize the main results obtained from the set of six case studies. It is hoped that this presentation contributes to the existing debate on trade and environment in three ways. First, we provide additional information on a range of actual regulatory issues that these countries are facing. These case studies show that the issues are ubiquitous, but often depend on fairly specific and often technical issues related to a specific subsector of the economy. Second, we show how policy analysts in developing can use a fairly simple methodology to begin to analyze these topics quantitatively and in a timely fashion to inform the policy debate. Finally, by looking at the results of the six country case studies as a whole, we begin to see how the magnitude of the effects depends on the details of the case.

The remainder of this paper is organized as follows. Section 2 provides a brief introduction to the case studies, which include a range of policy issues being driven by natural resource scarcity issues (e.g., water in Cyprus and Tunisia), environmental quality issues (water pollution in Morocco and Turkey), and environmental risks and product standards in exports markets (Syria and Jordan). Section 3 uses the Cypriot case study on irrigation water policy to introduce the partial equilibrium modeling approach used in the studies and to show in detail how the methodology is applied. Section 4 then summarizes some of the core results for the remaining case studies. Section 5 concludes. 


\section{CASE STUDY TOPICS}

The case study topics were chosen to include a range of sectors that are important for jobs, output and export earnings for the countries. The topics were also chosen to reflect a wide range of environmental issues - domestic resource scarcity issues, domestic environmental quality issues, and environmental risk issues in foreign markets - that these sectors are addressing now and/or are likely to have to address in the future. Regarding sectors, three case studies focus on agricultural markets: potato exports from Cyprus, fertilizer exports from Jordan, and date and citrus exports from Tunisia. The other three case studies focus on textile and leather markets: cotton-based textile product exports from Syria; cotton-based textiles product exports from Morocco; and tanned-leather exports from Turkey. A brief introduction for the case study topic for each country follows, with the countries focused on agricultural markets presented first followed by the textile/leather countries. ${ }^{2}$

\section{(a) Cyprus - A domestic resource scarcity issue}

The case study for Cyprus analyzes the impact on potato exports of higher prices for irrigation water. While representing only a small share of total GDP in Cyprus, agriculture remains important to the overall economy as an export earner. Agricultural commodities and various processed food products account for $35-40 \%$ of total exports, and fresh potatoes alone have accounted for half or more of the total value of agricultural exports since the early 1990s. The EU is the important foreign market for potatoes, mainly during the spring season when new potatoes produced in Cyprus are imported tariff-free into the EU.

Cyprus has suffered chronic water shortages for decades, and agriculture-potato farming in particular - has probably added to the stress on water supplies. Essentially all potato production relies on irrigation, with irrigation accounting for $70-75 \%$ of water use on the island. Farmers receive irrigation water at a highly subsidized rate from the Water Development Department. The average charge for irrigation water in 1998 was $\$ 0.13 / \mathrm{m}^{3}$, which is estimated to equal $34 \%$ of full delivery costs. Due to water scarcity, government-supplied irrigation water supply was reduced substantially reduced in 1998 and totally eliminated for potato growers in the southeastern coastal region.
With negotiations beginning in 1998 for accession to the EU, full accession will require among other things that Cyprus adopt EU environmental legislation. This could be problematic, especially in the case of existing water policies that highly subsidize irrigated agriculture. For example, the EU's framework directive on water policy calls for full cost recovery for water supplied to all users, including farmers. In short, the price of irrigation water should be high enough to cover all of the following: O\&M (operations and maintenance) costs; repair costs; loan payments; and a fund for improvements and extensions. On average, these costs are perhaps $\$ 0.40 \mathrm{~m}^{3}$ for government water supplies although they are much higher for newer water supply projects. In other words, with an average rate of $\$ 0.13 / \mathrm{m}^{3}$, prices in Cyprus would need to increase roughly $200 \%$ to about $\$ 0.40 / \mathrm{m}^{3}$ to become consistent with the water directive.

Given water scarcity issues in general in Cyprus, and the probable increase of water prices to farmers in the future, the Cypriot case study evaluated the impact of higher prices for irrigated water on production and exports of potatoes. While a $200 \%$ price increase anytime in the future is unlikely to be based on discussion between the case study team and government officials in Cyprus, the case study evaluated the impact on production and exports of three price changes $(20 \%, 40 \%$, and $60 \%)$.

\section{(b) Tunisia-A domestic resource scarcity issue}

The case study for Tunisia estimates the impact of higher irrigation water costs on exports of dates and citrus. Agriculture in Tunisia accounts for about $14 \%$ of total GDP. As with other countries in North Africa, the management of critical and limited water resources remains a key issue for economic growth and development of the economy. The cost of water to various sectors in the economy will surely rise in the future, either due to deterioration of supplies leading to increased access costs or policy induced increases in water resource costs.

Not surprisingly, however, producer associations basically oppose water cost increases to industry. The main concern is that any water cost increases will hurt their competitiveness, with a resulting reduction in exports and employment and an increase in imports. 
To evaluate this relationship between water costs and key exports, the Tunisian case study focused on the impact of higher water costs on fruit production and exports, and specifically, dates and citrus. For reference, fruit exports were about 73.2 million dinars in 1995 (about 1.1 dinars per \$1 US), which represented about $13.2 \%$ of total agricultural and food exports. Of total fruit exports, dates (fresh and dried) accounted for about $70 \%$ and citrus (mainly oranges) accounted for about $22 \%$.

\section{(c) Jordan-An issue of product standards in export markets}

The case study for Jordan estimates the impact of removing cadmium from phosphoric acid $\left(\mathrm{P}_{2} \mathrm{O}_{5}\right)$, which is then used in the production of fertilizers that are exported. The mining sector-mainly phosphate and potash - is an important sector of the Jordanian economy, which accounted for $7.5 \%$ of the GDP, about $7 \%$ of the industrial labor force, and about $36 \%$ of total exports as of 1996.

While there are currently four main phosphate mines in Jordan, the large and relatively new Shidiya mine has known reserves of 1.5 billion tons (annual mined output is less than nine million tons). As of 1996, about $97 \%$ of total fertilizer output (phosphate, potash, and manufactured fertilizers using these materials) were exported with a value of about US\$542 million. For reference, rock phosphate is exported directly and is used in the production of phosphoric acid, which in turn is a key input in the production of other fertilizers (e.g., diammonium phosphate (DAP)). The Jordanian Phosphate Mining Company (JPMC), which holds monopoly mining rights for phosphate mining that are renewed every 30 years, exported almost \$359 million in 1996, split roughly $50 / 50$ between phosphate rock and manufactured fertilizers.

Main export markets are in the EU and Asia, and Jordanian fertilizer exports are likely to face product standard issues in some of these markets in the future related to cadmium and radioactivity content. Both of these potentially hazardous materials are passed along in the production of phosphoric acid and then DAP. European countries and other locations have lowered the allowable cadmium content in fertilizer products over the past years, with the most stringent requirements found in Norway, Finland, Sweden and Switzerland.
The phosphate that is currently extracted from the Shidiya mine and to be extracted in the future has high enough cadmium levels to be of potential concern for the JPMC. Since the current strategy of the JPMC is to focus production of the phosphate rock in the Shidiya mine, the removal of cadmium will probably become a management concern in not-too-distant future.

The total removal of cadmium from rock phosphate directly is considered technically impractical and uneconomic. But, there are several processes being developed for the removal of cadmium from phosphoric acid, including: cocrystalization of cadmium with anhydrite (estimated cost is US\$8 per ton), precipitation of cadmium with sulfides (estimated cost is US\$15 per ton), ion-change resins (estimated cost is US\$35 per ton), and solvent extraction (estimated cost is US\$26 per ton). These costs do not include any domestic disposal cost associated with managing the solid waste (e.g., the cadmium). With phosphoric acid prices in the range of $\$ 219$ per ton in 1997 , these additional cadmium removal costs could represent a $2.5-10 \%$ increase in the cost of phosphoric acid used as an input in fertilizer production.

\section{(d) Morocco-A domestic environmental quality issue}

The case study for Morocco estimates the impact on production and exports of textile products if new water effluent standards for the sector were developed and enforced. As background, textiles are a key sector of the Moroccan economy, accounting for almost $30 \%$ of all industrial enterprises located mainly in $\mathrm{Ca}-$ sablanca, Fez, Rabat, Settat and Marrakech. The sector of almost 1,400 facilities involves four related production segments (spinning, weaving, dying, and garment assembly). As of 1996, total textile exports were about 13 billion dirhams, with almost $70 \%$ of total exports destined for Europe. Garments, however, accounted for over $55 \%$ of the value of total production and almost $81 \%$ of total textile exports (about 10.4 billion dirhams as of 1996).

The government of Morocco is currently in the process of developing water effluent standards for various industries in the country, with biological oxygen demand (BOD) being identified as a likely pollutant to be regulated in the textile sector (mainly due to effluents in the dying stage). Existing estimates in Morocco of 
total BOD5 levels in water effluent are between 26,000 and 58,000 tons per year, with the textile sector accounting for perhaps 3,900-8,700 tons per year. Based on existing estimates of BOD5 control costs per ton, the Moroccan case study considers the impact on production and exports of textiles of creating and enforcing modest BOD5 effluent standards on the textile sector.

\section{(e) Syria-An issue of product standards in domestic and export markets}

The case study for Syria estimates the impact of the existing Syrian ban on the use of carcinogenic azo dyes on the production and export of textile products. Syria produces and exports cotton, cotton yarns, cotton fabrics, and garments. The dying process in the production of yarns and fabrics is one of the more pollution-intensive components of the textile industry, mainly in terms of water effluents. In 1996, Syria banned the importation (and de facto use) of carcinogenic azo dyes. While the ban has been enforced, the original motive for the ban is not clear. The government could have taken the action to maintain continued access for the country's exports to the German market, which banned the use of azo dyes in about 1994, although there was no EU-wide azo dye ban in either 1994 or 1996. If Syrian policy changed to maintain market access for exports to Germany, this case study provides a good example of how a product standard in an export market (azo-free textiles products) effectively becomes a process standard in the producing country. Of course, the government may also have banned imports (and domestic production) due to concerns for the citizens health in the country.

While dyes can be applied to either yarn or fabric, the Syrian case study focused its analysis on the dying process in the production of fabrics (considered relatively more important in Syria). In this case, the azo dye ban forced domestic fabric producers to use more expensive substitute dyes. Since more domestic fabric is consumed within the country, mainly as an input in the garment industry, the impact of azo dye ban on garment exports is evaluated.

\section{(f) Turkey-A domestic environmental quality issue}

The case study for Turkey estimates the impact on production and exports of leather products if existing water effluent standards were actually enforced on the sector. Turkey is one of the world's larger producers of leather. The sector, which contains about 1,200 facilities, is divided between formal sector enterprises in organized industrial zones (about $80 \%$ ) and small-scale facilities $(20 \%)$. As of 1995 , the sector accounted for about $1.8 \%$ of manufacturing output, almost $4 \%$ of total exports, and about $5 \%$ of employees covered by the country's social security system. About $75 \%$ of Turkish leather exports are to the EU, with $44 \%$ of total exports going to Germany alone.

Leather production is pollution intensive. From raw hide and skin preservation to soaking, unhairing, liming, and tanning, a range of water pollutants are generated including: total suspended solids, BOD, chemical oxygen demand, $\mathrm{pH}$, phosphorus, total chromium, chromium +VI, nitrogen, oil and grease, and phenol.

While Turkey has already adopted water effluent standards for tanneries that were modeled in part from German effluent standards, existing available data suggest that actual effluent levels substantially exceed standards. As a result, while producers in organize industrial zones have waste water treatment facilities, such facilities either are not used or are not capable of handling the effluent load form the tanneries. Such a situation in principle is not consistent with the customs agreement between the EU and Turkey.

\section{APPLYING THE METHODOLOGY USING THE CASE STUDY FOR CYPRUS}

The effects of more stringent environmental regulations, such as higher water prices, on production and exports can be discussed quite easily in a simple demand and supply context. Three situations or possibilities are considered in the case studies: a basic partial equilibrium analysis; an extension that allows for firm-level inefficiency improvements to be induced by the regulatory change; and an extension that allows for equilibrium price adjustments in export markets. Each situation is developed in turn, and the information from the Cypriot case study is used to show in detail how the methodology is implemented.

\section{(a) The "basic" partial equilibrium approach}

Consider the simple market situation in Figure 1, where $S^{0} S^{0}$ is an initial supply 


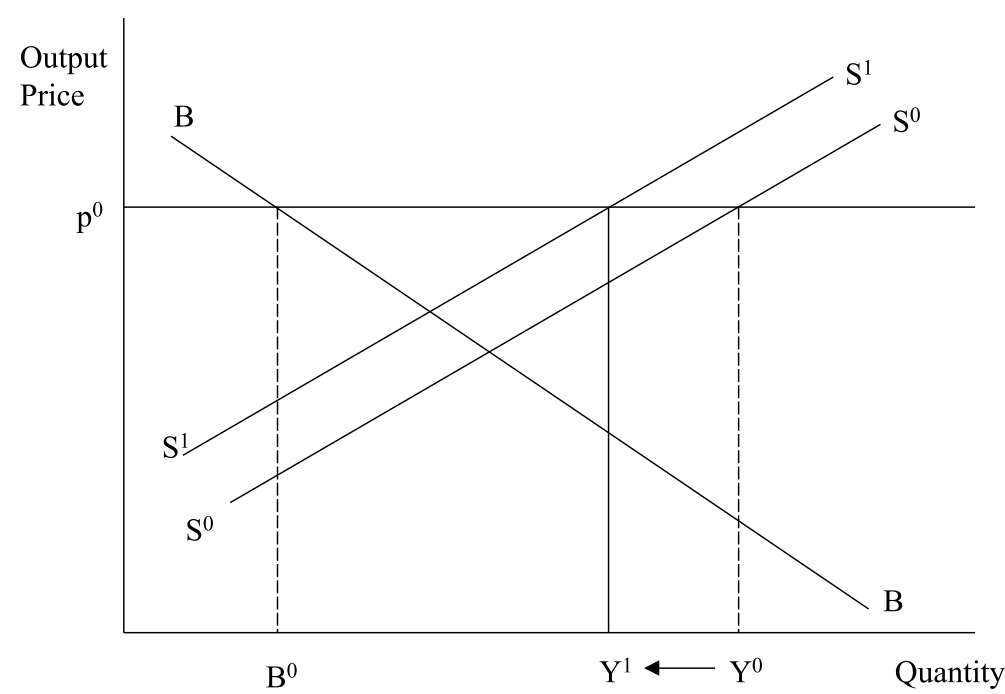

Figure 1. Environmental regulations raise costs, reduce production and reduce exports.

schedule for potatoes in Cyprus, $p^{0}$ is a constant export price for potatoes, BB represents domestic demand in Cyprus, and $E^{0}=Y^{0}-B^{0}$ is the existing level of exports of potatoes to the EU. In Figure 1, domestic policy changes (i.e. higher water prices) increase production costs and, therefore, shift domestic supply from $S^{0} S^{0}$ to a new level $S^{1} S^{1}$. Given a fixed price at $p^{0}$, domestic production falls from $Y^{0}$ to $Y^{1}$ and exports fall from $E^{0}=Y^{0}-B^{0}$ to $E^{1}=$ $Y^{1}-B^{0} .{ }^{4}$

While in principle it is possible to estimate directly a reduction in past production and/or exports due to past changes in some environmental regulation, the data needed to estimate such relationships are difficult to obtain in many developing and transition economies. In such countries, however, the past is not as relevant as the future. The public policy concern, for example regarding water pricing in Cyprus, focuses on how policy changes in the future might alter production and exports in the future.

To analyze these forward-looking questions quantitatively, Larson (2000) shows how to use some microeconomic foundations to decompose supply shifts in Figure 1 into separate components that can be easily understood. Some of these components can be calculated directly, while others need to be estimated and/ or approximated depending upon data availability and purpose of the analysis. With this decomposition, policy scenarios can be devel- oped to simulate trade effects if such environmental policy changes were implemented. The results of this policy analysis can provide relevant information in a timely fashion to ongoing environmental and trade policy debates in developing countries.

Since the Cypriot case study and the MedPolicies case studies in general used the Larson (2000) approach, the main logic of this approach is summarized here. The methodological overview provided here is simply intended to help the reader understand and evaluate the results presented for the case studies. The presentation and notation used here is perhaps easier to follow than in the original article. Moreover, all of the empirical analysis discussed in this paper is new and was not contained in Larson (2000).

Larson (2000) begins by assuming that firms (e.g., the potato producers in Cyprus) try to minimize costs and maximize profits within the context of competitive markets. As a result, if some input $X$ (water) becomes more costly due to a policy change (higher water prices), the links between profit and costs functions can be used to estimate the resulting shift in the supply.

The basic notation is:

$X \quad$ the regulated input used by some industry (water in the Cyprus analysis)

$w \quad$ the initial regulated input price (water price) 
$K$

other inputs (e.g., fertilizer, seeds, labor)

$r \quad$ fixed prices of other inputs

$Y \quad$ output (spring season potatoes in the Cyprus analysis)

$f(X, K)$ a production function relating inputs to output, with $Y=f(X, K)$

$p$ the output price.

With the above notation and the assumptions that producers minimize costs and maximize profits within the context of competitive markets, the profit function is $\pi=\pi(p, w, r)$ and the cost function is $C=C(w, r, y)$, where $y$ is any reference level of output.

Using the envelope theorem (Hotelling's Lemma for the profit function and Sheppard's Lemma for the cost function), we also know that $Y=Y(p, w, r)$ is the profit-maximizing supply function for potatoes, $X=X(p, w, r)$ is the profit-maximizing water demand function, and $X^{\mathrm{c}}=X^{\mathrm{c}}(w, r, y)$ is the cost-minimizing input demand function for any level of output $y$. When $y$ is evaluated at the profit-maximizing supply level $Y$, we also know that $X(p, w, r)=$ $X^{\mathrm{c}}(w, r, Y(p, w, r))$.

For policies that affect a specific input (such as water), let some initial regulatory situation be denoted as $R^{0}$, and let the input price be denoted as $w^{0}=w\left(R^{0}\right)$ based on this regulatory situation. For example, initial water prices are $w\left(R^{0}\right)=\$ 0.13 \mathrm{~m}^{-3}$ for the Cypriot case study. If water policies change from $R^{0}$ to $R^{1}$, then the new price becomes $w^{1}=w\left(R^{1}\right)$. As a result, the environmental regulatory change from $R^{0}$ to $R^{1}$ implies a price change $\mathrm{d} w=w^{1}-w^{0}$, which in percentage terms can be written as $\mathrm{d} w / w^{0}=$ $\left(w^{1}-w^{0}\right) / w^{0}$. As noted above, three scenarios are evaluated in the Cypriot case study based on $\mathrm{d} w / w^{0}=20 \%, 40 \%$, and $60 \%$. Based on these policy scenarios, the goal here is to evaluate (calculate, or approximate, or estimate) the shift in supply, $\mathrm{d} Y=Y^{1}-Y^{0}$, from this policy-induced change in the price of the regulated input (water).

To begin to evaluate this shift in supply, the symmetry of the Hessian of $\pi$, can be used to show that:

$\frac{\partial Y}{\partial w}=-\frac{\partial X}{\partial p}=-\frac{\partial X^{\mathrm{c}}}{\partial y} \frac{\partial Y}{\partial p} \leqslant 0$

where $\partial Y / \partial w$ shows the shift in potato supply from a change in the water price, $-\partial X / \partial p$ shows the negative of the effect of higher potato prices on water demand. These two expres- sions are equal $(\partial Y / \partial w=-\partial X / \partial p)$ because the Hessian matrix of second-partial derivatives of the profit function is symmetric in prices. The last expression in (1) makes use of the fact that $X(p, w, r)=X^{\mathrm{c}}(w, r, Y(p, w, r))$.

The result in (1) can be rewritten in elasticity form as:

$\eta_{y w}=\frac{\partial Y}{\partial w} \frac{w}{Y}=-\left[\frac{w X}{C}\right]\left[\frac{C}{p Y}\right] \eta_{y p} \eta_{x y}^{c}$

where $\eta_{y w}=(\partial Y / \partial w)(w / Y)$ is the percentage change in potato supply for a $1 \%$ increase in water prices; $w X / C$ is water cost as a share of total production costs; $C / p Y$ is simply costs over revenues; $\eta_{y p}=(\partial Y / \partial p)(p / Y)$ is the percentage change in potato supply for a $1 \%$ change in potato price, and $\eta_{x y}^{\mathrm{c}}=\left(\partial X^{\mathrm{c}} / \partial y\right) \times$ $(Y / X)$ is the percentage change in cost-minimizing level of water demand for a $1 \%$ increase in output level. ${ }^{5}$

Defining $\theta=(p Y-C) / C$ as the percentage of profits over production costs, which can be rearranged to yield $C / \mathrm{pY}=1 /(1+\theta)$, and defining $S_{x}=w X / C$ as the water cost share, Eq. (2) can be written more simply as:

$\eta_{y w}=-S_{X}\left(\frac{1}{1+\theta}\right) \eta_{y p} \eta_{x y}^{\mathrm{c}}$

For some policy changes that increase the cost of the regulated input by any percentage $\mathrm{d} w / w^{0}$ discussed above, the cross-price elasticity in (3) can be used to project the percentage change in output as:

$\frac{\mathrm{d} Y}{Y^{0}}=\eta_{y w} \frac{\mathrm{d} w}{w^{0}}$

where $Y^{0}$ and $w^{0}$ are the initial input price and output level before the policy change.

Finally, potato exports are equal to production minus domestic consumption $(E=Y-B)$, so that the change in exports is $\mathrm{d} E=\mathrm{d} Y$. In percentage terms, the change in exports from the water policy change can be estimated as:

$\frac{\mathrm{d} E}{E^{0}}=\frac{\mathrm{d} Y}{Y^{0}} \frac{1}{\left(E^{0} / Y^{0}\right)}$

The relationships in Eqs. (3)-(5) show that the impact of more stringent environmental policies on exports in this simple partial equilibrium world depends on five specific pieces of information:

- the supply elasticity with respect to output price, $\eta_{y p}$;

- the regulated input's cost as a share of total costs, $S_{X}$; 
Table 1. Basic information, parameter assumptions, and results for the Cypriot case study

\begin{tabular}{|c|c|c|c|}
\hline & Notation & Scenario 1 & Scenario 2 \\
\hline \multicolumn{4}{|l|}{ Basic information } \\
\hline Output & $Y$ & Potatoes & Potatoes \\
\hline Regulated input & $X$ & Water & Water \\
\hline Supply elasticity & $\eta_{Y p}$ & 0.150 & 1.000 \\
\hline Input cost share & $-S_{X}$ & -0.050 & -0.050 \\
\hline Profitability factor & $1 /(1+\theta)$ & 0.580 & 0.833 \\
\hline Returns to scale factor & $\eta_{X Y}^{\mathrm{c}}$ & 2.000 & 1.100 \\
\hline \multicolumn{4}{|l|}{ Basic model results } \\
\hline Cross price elasticity from Eq. (3) & $\eta_{Y w}$ & -0.009 & -0.046 \\
\hline Policy scenario: a $60 \%$ increase in water price & $(\mathrm{d} w / w) \times 100$ & 60.000 & 60.000 \\
\hline Percentage change in potato production from Eq. (4) & $\mathrm{d} Y / Y$ & -0.525 & -2.767 \\
\hline Export share of total production & $E / Y$ & 0.800 & 0.800 \\
\hline Percentage change in potato exports from Eq. (5) & $\mathrm{d} E / E$ & -0.656 & -3.458 \\
\hline \multicolumn{4}{|l|}{ Including export price adjustments } \\
\hline Domestic demand elasticity & $\eta_{B p}$ & -0.500 & -1.000 \\
\hline Domestic consumption as share of total production & $B / Y$ & 0.200 & 0.200 \\
\hline Export demand elasticity & $\eta_{D p}$ & -6.000 & -10.000 \\
\hline Exports as a share of total production & $E / Y=D / Y$ & 0.800 & 0.800 \\
\hline Export price elasticity from (7) & $\eta_{p w}$ & 0.002 & 0.005 \\
\hline Final supply elasticity with respect to the input price from (8) & $\Omega_{Y w}$ & -0.008 & -0.041 \\
\hline Final export elasticity with respect to the input price from (8) & $\eta_{E w}$ & -0.010 & -0.050 \\
\hline Final $\%$ change in output & $\mathrm{d} Y / Y$ & -0.509 & -2.466 \\
\hline Final $\%$ change in exports & $\mathrm{d} E / E$ & -0.624 & -3.007 \\
\hline
\end{tabular}

- the profitability of the industry, represented by the term $1 /(1+\theta)$;

- the returns to scale of the industry (see footnote 2), represented by the input demand elasticity (cost-minimizing) with respect to output level, $\eta_{x y}^{\mathrm{c}}$; and

- the actual regulatory impact on input costs, $\mathrm{d} w / w^{0}$.

Table 1, under the heading "basic information," provides the initial values for these six pieces of information used in the Cypriot study. First, supply elasticities are not that difficult to estimate if data are available, and it is common practice in international trade studies to borrow elasticities from the existing literature to develop elasticity estimates for simulation and policy analyses (see, e.g., Sullivan, Wanio, \& Roningen, 1989). Even though potatoes are a key crop in Cyprus, there has been surprisingly little analysis of supply response in the sector. As a result, it was not possible to borrow a potato supply elasticity with respect to price from some previous study. Rather than borrowing an elasticity from some other country, the Cyprus case study used annual price and quantity information from government statistics to estimate a supply elasticity of $\eta_{y p}=0.15$. $^{6}$ This elasticity estimate is used in Scenario 1 reported in Table 1. Given the lack of prior knowledge regarding this elasticity, however, Scenario 2 reported in Table 1 considers a larger elasticity of $\eta_{y p}=1.00$. The importance of precision of such numbers will be discussed after the basic information and results are presented.

Second, based on reported data from the HIID (2000, p. 222) water costs are on average about $5 \%$ of total potato production costs. Third, regarding profitability, reported data from the HIID (2000, p. 222) suggest that, on average, spring season potato production is highly profitable, with $\theta=0.72$ so that $1 /(1+$ $\theta)=0.58$. This $72 \%$ level of profits above costs seems large, especially since the reported cost information includes variable costs, fixed costs, and returns to family labor. To consider the implications of lower profitability, Scenario 2 assumes a profit rate of $20 \%$, so that $\theta=0.20$ and $1 /(1+\theta)=0.833$.

Fourth, there is no direct information regarding returns to scale in potato production. Intuitively, returns to scale and supply elasticities are related. Sectors with close to constant returns to scale have large supply elasticities, while firms with more decreasing returns to scale have smaller supply elasticities. As a result, for Scenario 1 in Table 1, the relatively 
small supply elasticity of $\eta_{y p}=0.15$ is combined with relatively strong decreasing returns to scale at $\eta_{x y}^{\mathrm{c}}=2.00$. For Scenario 2 in Table 1 , the larger supply elasticity of $\eta_{y p}=1.00$ is combined with closer to constant returns at $\eta_{x y}^{\mathrm{c}}=1.10$.

Fifth, regarding the policy scenario, a $60 \%$ increase in water price is evaluated in Table 1. While it was fairly easy to identify a policyrelevant price increase for the Cyprus case based on discussions with the Ministry of Agriculture and others in Cyprus, it is noted here that this piece of information is often the most difficult and potentially confusing piece of information needed for the analysis. On the one hand, average notions of "strictness" used in trade and environment literature, such as in Tobey (1990), are not precise enough to evaluate actual changes in policies on production incentives and trade. On the other hand, engineering-like estimates of costs of meeting new regulations tend to overestimate actual costs and do not take into account the fact that governments regularly subsidize firms to undertake such actions.

Returning to Table 1, under the heading "Base Model Results," the results for the Scenario 1 analysis suggests that a $60 \%$ increase in water prices to irrigated potato farmers would change potato production by $-0.53 \%$ and exports by $-0.66 \%$. For Scenario 2, however, the same policy change would lead to a $-2.77 \%$ reduction in production and a $-3.46 \%$ reduction in exports. While the trade impact for Scenario 1 are minor, the $3.5 \%$ reduction in exports in Scenario 2 is probably large enough to be considered a "big" impact.

The usefulness of this case study analysis for Cyprus, and the other countries as well, is the ease with which scenarios can be developed and analyzed. Ranges of policy options are usually under discussion at any point in time, and the various groups involved in the policy process may have different opinions regarding key parameters and assumptions of any analysis.

With Table 1 set up in any standard spreadsheet program, "what if" questions can be asked during meetings with different stack holders involved in (and impacted by) policy changes. Better information can be incorporated on the spot, and the discussion can focus on the pieces of information that are considered to be the least precisely known. As discussed in the Cypriot case study, for example, a price increase of only $20 \%$ is perhaps a likely first step in the process of raising water prices. With just a 20\% water price increase, exports are calculated to fall by only $-0.22 \%$ for Scenario 1 and about $-1.15 \%$ for Scenario 2. Given that Scenario 1 is probably a better representation of the current situation in Cyprus, a modest water price increase would have negligible impacts on the level of production and exports of potatoes.

\section{(b) Including efficiency improvements}

If environmental regulations increase an input price, as discussed above, companies may have an incentive to increase the efficiency with which the input is used. In general, such efficiency improvements act to offset some of the impacts on the sector of the input price increase due to environmental regulations (see, e.g., Porter, 1990). This efficiency effect can be described as a simple shift in supply functions as outlined in Figure 2. In Figure 2, the direct impact of higher input prices on production and export is a shift back in the supply function from $S^{0} S^{0}$ to $S^{1} S^{1}$ as in Figure 1. As a second impact, however, efficiency improvements associated with the input price increase act to shift out the supply function to $S^{2} S^{2}$ with new production levels $Y^{2}$ with exports $E^{2}=Y^{2}-B^{0}$. Thus, efficiency improvements act to mitigate some of the adverse impacts on exports of some environmental policy change. Appendix A provides additional details on how to include efficiency improvements into the analysis.

While a possibility in general, the Cypriot case study did not include efficiency improvements in the analysis of water pricing. Existing information from the Ministry of Agriculture, Natural Resources and the Environment (see HIID, 2000, p. 10) suggests that modern, water efficient irrigation technologies are already used on $95 \%$ of the irrigated area in the country. Opportunities for further efficiency improvements in water use are limited even if water prices rise.

\section{(c) Differentiated products and export price adjustments}

As noted in Larson (2000), there are two simple reasons why export prices may adjust as domestic production shifts in response to environmental regulatory changes. First, by definition, changes in export supply from a "large country" will influence international prices for 


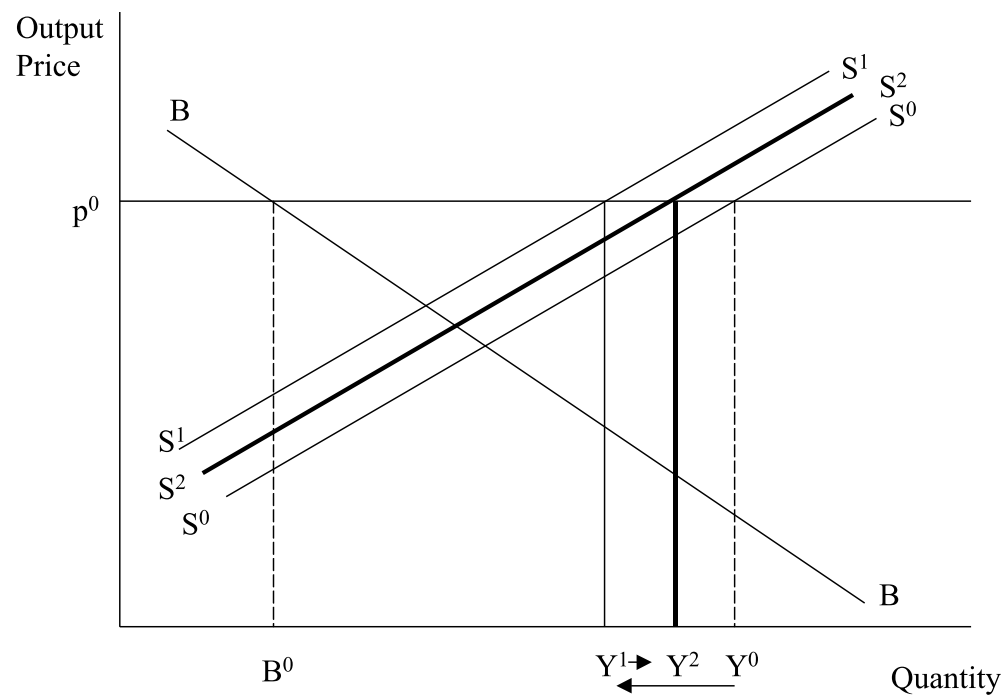

Figure 2. Efficiency improvements can reduce costs, increase production and increase exports.

that product (Van Beers \& Van den Bergh, 1996). Second, products may be differentiated by country of origin (e.g., Armington, 1969), among other reasons. Given that Cypriot potatoes are considered to be of very good quality in the EU and, as a result, have sold at premium prices compared to other competitors (see, HIID, 2000, p. 221), this notion of differentiated products seems highly relevant for the Cyprus case study. As a result, shifts in do- mestic production and export supply may affect the price received for exports (see, Dervis, deMelo, \& Robinson, 1989, p. 225).

Figure 3(a) for the domestic market and (b) for the export market show how to include export price adjustments into the analysis, with the sector now facing a "downward sloping" export demand schedule DD in (b). As environmental policy changes lead to shifts in domestic supply from $S^{0} S^{0}$ to $S^{1} S^{1}$, for example,

(a)

The Domestic Market

(b)

The Export Market

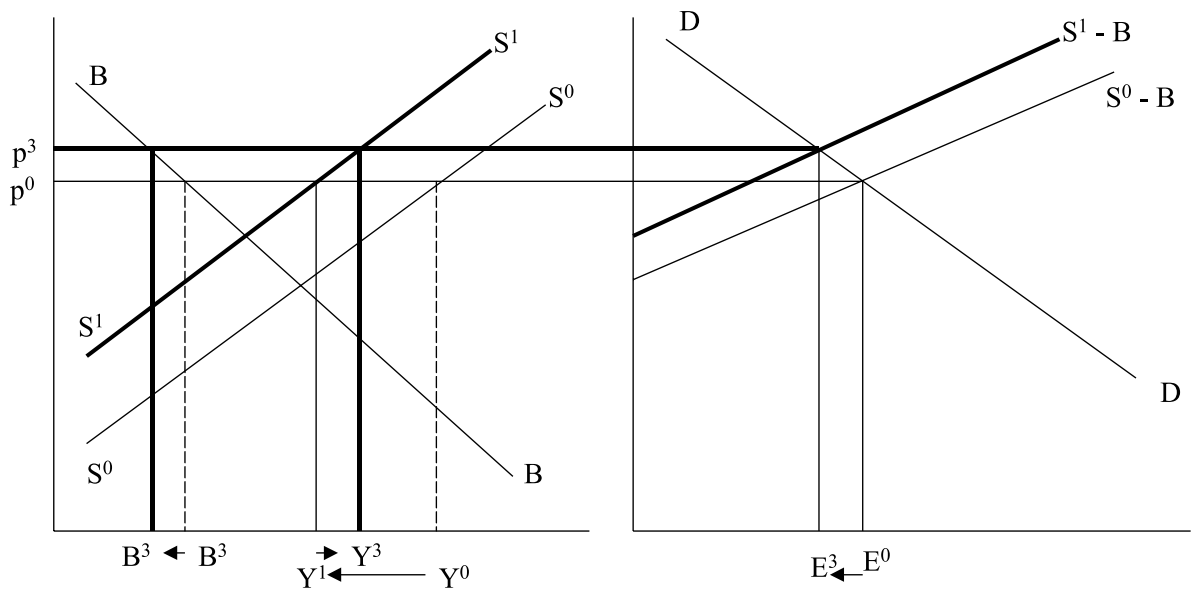

Figure 3. Including export price adjustments. 
export prices adjust in Figure 3(b) from $p^{0}$ to $p^{3}$. With this export price increase, domestic production increases to $Y^{3}$, domestic demand falls to $B^{3}$, and the overall change in exports is from $E^{0}=Y^{0}-B^{0}$ at price $p^{0}$ to $Y^{3}-B^{3}$ at price $p^{3}$.

For additional notation for Case 3, let $D=D(p)$ represent export demand as a function of price (e.g. EU demand for Cypriot potatoes), and let $B=B(p)$ represent domestic demand as a function of domestic price. Assuming the export market clears where $D(p)=$ $Y(p, w, r)-B(p)$, the equilibrium export price in local currency will be $p=p(w, r)$.

After taking the total differential of the equilibrium condition with respect to $p$ and $w$, the impacts of higher input costs due to more stringent environmental regulations on price $p$ can be written as:

$\eta_{p w}=\left[\frac{\eta_{y w}}{\eta_{B p} \frac{B}{Y}-\eta_{y p}+\eta_{D p} \frac{E}{Y}}\right]$

where $\eta_{D p}$ is the elasticity of export demand with respect to the product's price, $\eta_{B p}$ is the elasticity of domestic demand with respect to price, $B / Y$ is the share of domestic consumption in total production, and $E / Y$ is the share of exports in total production. In effect, the elasticity in (6) shows how much of the regulatoryinduced input price increase is passed along to consumers in the export market.

Writing the expanded form of the supply function as $Y=Y(p(w, r), w, r)$ and of the export supply function as $E=Y(p(w, r), w, r)-$ $B(p)$, the basic result for Case 3 is that:

$$
\begin{aligned}
& \Omega_{y w}=\eta_{y w}+\eta_{y p} \eta_{p w} \quad \text { and } \\
& \Omega_{E w}=\Omega_{y w} \frac{1}{(E / Y)}-\eta_{B p} \eta_{p w} \frac{(B / Y)}{(E / Y)}
\end{aligned}
$$

where the overall supply elasticity with respect to input price $w\left(\Omega_{y w}\right)$ is simply the Case 1 elasticity $\eta_{y w}$ plus the own-price elasticity of supply times the export price elasticity with respect to the input price defined above. The export supply elasticity, $\Omega_{E w}$, now takes into account supply changes and consumption changes induced by the policy. ${ }^{7}$ In Table 1 under the heading "including export price adjustments," for Scenario 1 it assumed that domestic potato demand is fairly inelastic $(-0.5)$, while export demand is fairly elastic (-6). Again, for policy analysis purposes, there are not to the authors' knowledge existing studies that report estimates of these elasticities for Cyprus. ${ }^{8}$ Thus, Scenario 2 is also developed with larger demand response both in the domestic $(-1.0)$ and export markets $(-10)$. In general, lower demand response allows more of the regulatory costs to be passed along to consumers in both the domestic and international market, while higher larger demand response allows less of the cost to be passed along.

Using these Scenarios, the results for Scenario 1 shows that $\eta_{p w}=0.002$, so that a $60 \%$ increase in water prices to irrigated potato farmers would increase export prices by only $0.12 \%$. This minor increase in price, due in part to the minor production impact, mitigates some of the production and export decline. For Scenario 2, even though demand is more responsive to price in both markets, the final effect on prices is larger $\left(\eta_{p w}=0.005\right)$, due mainly to the higher original supply impact described in Figure 1. With a $60 \%$ increase in water prices, export prices increase by $0.30 \%$ and exports fall by $-3.007 \%$ overall. Thus, this relatively minor export price increase is large enough to moderate some substantial amount $(18 \%)$ of the original reduction for the basic model.

\section{A SUMMARY OF RESULTS FOR THE SIX COUNTRIES}

The above methodological discussion and application in the Cyprus case study provides an introduction to the logic used in the case studies. For all case studies, information for the basic model was developed. This information, which is summarized for all countries in Table 2 , was simply the starting point for the analysis. In most cases, input cost shares, estimates of regulatory-induced cost changes, and profitability were obtained from government sources and/or direct discussion with industry leaders. Information on supply elasticities and returns to scale were more difficult to obtain, as noted above. For each case study a group of scenarios were developed to explore a reasonable range of possible outcomes.

Table 3 summarizes the range of impacts obtained for the six case studies. As noted in Column one of Table 3, information for the three agricultural studies (Cyprus, Jordan, and Tunisia) is provided first, followed by the studies focused on textile and leather sectors (Morocco, Turkey, and Syria). 
Table 2. Base information for country studies (all numbers rounded to two decimal places)

\begin{tabular}{|c|c|c|c|c|c|c|c|c|}
\hline & & \multicolumn{2}{|c|}{ Cyprus } & \multirow{2}{*}{$\begin{array}{c}\text { Jordan } \\
\text { Fertilizers }\end{array}$} & \multirow{2}{*}{$\begin{array}{c}\text { Syria } \\
\text { Garments }\end{array}$} & \multirow{2}{*}{$\begin{array}{c}\text { Morocco } \\
\text { Textiles }\end{array}$} & \multicolumn{2}{|c|}{ Tunisia } \\
\hline Output & $Y$ & Potatoes & Potatoes & & & & Dates & Citrus \\
\hline Regulated input & $X$ & Water & Fertilizer & $\mathrm{P}_{2} \mathrm{O}_{5}$ & Dyes & Water & Water & Water \\
\hline Supply elasticity & $\eta_{Y p}$ & 0.15 & 0.15 & 0.50 & 1.90 & 2.00 & 1.00 & 0.50 \\
\hline Cost share & $-S_{X}$ & -0.05 & -0.05 & -0.25 & -0.75 & $-0.00^{\mathrm{a}}$ & -0.16 & -0.07 \\
\hline Profitability factor & $1 /(1+\theta)$ & 0.58 & 0.58 & 1.00 & 1.00 & 1.00 & 1.00 & 1.00 \\
\hline Returns to scale factor & $\eta_{X Y}^{\mathrm{c}}$ & 2.00 & 2.00 & 1.10 & 1.10 & 1.10 & 1.50 & 1.50 \\
\hline Export share of output & $E / Y$ & 0.80 & 0.80 & 1.00 & 0.30 & 0.80 & 0.27 & 0.53 \\
\hline Efficiency improvements & $\eta_{q w}$ & 0.00 & 0.60 & 0.00 & 0.10 & 0.50 & 0.10 & 0.10 \\
\hline $\begin{array}{l}\text { Domestic price elasticity } \\
\text { of demand }\end{array}$ & $\eta_{B p}$ & -1.00 & -1.00 & 0.00 & -2.00 & -2.00 & -4.00 & -4.00 \\
\hline $\begin{array}{l}\text { Export price elasticity of } \\
\text { demand }\end{array}$ & $\eta_{D p}$ & -6.00 & -6.00 & -10.00 & -10.00 & -10.00 & -10.00 & -10.00 \\
\hline
\end{tabular}

${ }^{\mathrm{a}}$ For Morocco, the water effluent cost share is only $0.1 \%$ of production costs, which due to rounding is noted as 0.00 in Table 2.

Besides water pricing, the Cypriot case study also included an analysis of the impacts of higher fertilizer prices on potato production and exports. Table 3 for Cyprus shows that higher fertilizer costs (due to EU nitrate policy for groundwater protection) would have minor impacts on potato production and exports. The main reason is that the existing irrigation technology would allow for the easy adoption of fertilizer application through the drip irrigation systems (fertigation). This technology switch involves substantial efficiency improvements in the use of fertilizers, which from Table 3 could imply almost no impact on production and exports. For this case, it is possible to observe efficiency improvements in the use of fertilizers due to "fertigation" large enough to offset completely the fertilizer price increase, thereby leading to minor production increases (an empirical example that is consistent with the so-called Porter hypothesis).

For Jordan, fertilizer exports (DAP) could be affected by the additional costs of removing cadmium, depending on actual removal costs in the future. Since phosphoric acid $\left(\mathrm{P}_{2} \mathrm{O}_{5}\right)$ accounts for about $25 \%$ of the costs of producing DAP, higher $\mathrm{P}_{2} \mathrm{O}_{5}$ costs are important. If low cost approaches are viable, so that $\mathrm{P}_{2} \mathrm{O}_{5}$ production costs only rise by about $2.5 \%$, and if such costs are passed along to the DAP production stage, the impact on production and exports of DAP fertilizer would be minor (perhaps an export decline of $0.3 \%$ ). If removal costs are actually higher, so that $\mathrm{P}_{2} \mathrm{O}_{5}$ price rises by perhaps $10 \%$, then the fall in production and exports could be about $1.3 \%$. There is substantially uncertainty, however, about sup- ply response in the fertilizer industry. Table 3 shows that exports could fall by about $6.5 \%$ with high-cost cadmium removal, higher supply response, and decreasing returns to scale due to capacity constraints.

For Morocco, the proposed increase in BOD control costs would have a minor impact on textile production and exports, and there is little variation in the outcomes. The logic of this outcome is clear. BOD control costs are currently almost zero, perhaps between $0.09 \%$ and $0.15 \%$ of production costs. At the same time, the proposed BOD effluent standard policy would involve minor increases in BOD control costs. As a result, minor increases in water control costs, due to the initiation of modest water effluent control policies in the textile sector, would probably have minor impacts on overall production levels and exports.

Caution is needed, however, in the interpretation of the Moroccan case study because the study assumes that capital costs for BOD control would be subsidized by the government, while the industry would only pay operating and maintenance costs. If the relevant policy option was more stringent BOD effluent standards along with the private sector paying both investment and operating costs, it would be easy to envision a future where effluent control costs reached $2-5 \%$ of total production costs. Using the average cost model discussed in Appendix A, such cost increases could reduce exports by about $5-11 \%$. Thus, this Moroccan study emphasizes that environmental policies per se are not the issue; rather it is necessary to be clear on both the stringency of the policy 
and the allocation of financial responsibility for complying with the policy.

The range of results for Tunisia, Turkey, and Syria show that, for some countries, a rather wide range of potentially substantial impacts could occur depending on specific pieces of information and proposed policy changes. For example, from Table 3, higher water costs for irrigation in Tunisia could have some important impact on production and exports. For a $50 \%$ increase in water costs, the analysis suggests that exports could fall between $2 \%$ and $4 \%$ for citrus and $14-26 \%$ for dates. This difference depends on the fact that water has a higher cost share for dates as compared to citrus and the case study suggests that supply response is less for citrus as compared to dates.

The large range of negative impacts on leather exports for Turkey is driven by the rather large cost change associated with the proposed policy change (equivalent to $2-6 \%$ of total production costs), the minor share of production that is exported $(25 \%$ of production exported), and the rather large supply response used in the analysis based on previous studies. The Turkish study also emphasizes the importance of being able to pass along some of the production cost increase through higher output prices. For example, the high-cost policy scenario (water cost equal to $6 \%$ of total costs) is estimated to reduce exports by $45 \%$ if export price is fixed. With international price adjustments, based on elasticities reported previously in the literature, this result falls from $45 \%$ to $7 \%$. While $7 \%$ is still rather large in absolute terms, it is substantially smaller than with no price adjustments. With the lower-end cost increase of $2 \%$ of total production costs, this impact with international price adjustments is $2.3 \%{ }^{9}$

For Syria, the policy to ban the use and importation of azo dyes raised dye costs by about $35 \%$ (i.e., the price differential for azo-free substitutes). With dyes accounting for about $20 \%$ of fabric production costs, the case study estimates that the domestic fabric price would rise between $4 \%$ and $9 \%$ depending on fabric supply response, domestic fabric demand (as an input into garment production) and returns to scale in fabric production. Given that fabrics represent about $75 \%$ of garment costs in Syria, this fabric price increase is estimated to reduce garment production by $4-10 \%$. Given that about $30 \%$ of garment production is exports, the percentage drop in exports is substantially larger $(9-22 \%)$.

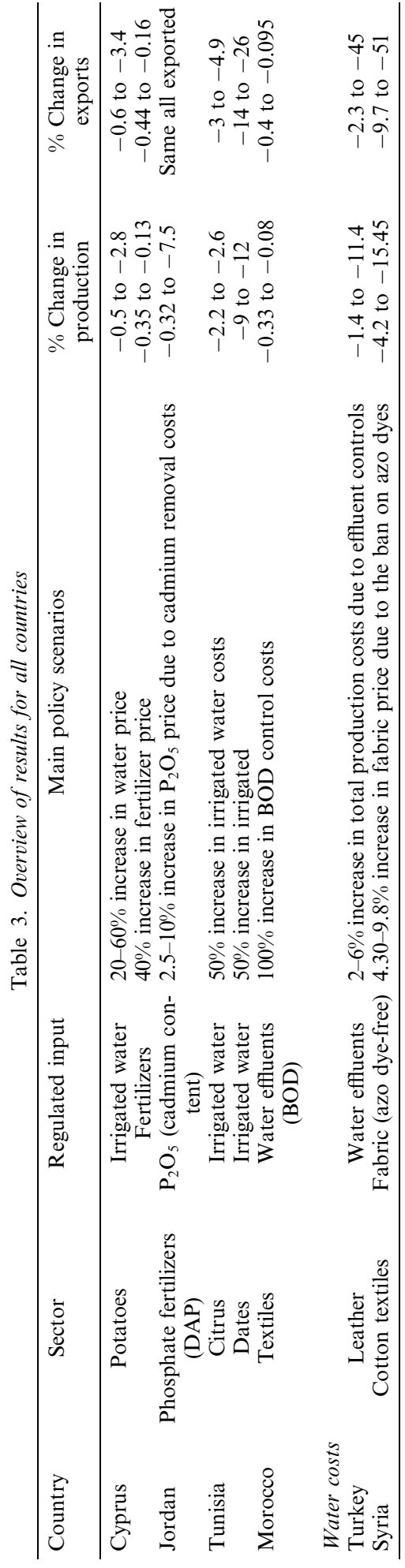




\section{FINAL COMMENTS}

The impact of environmental regulations on exports depends on the details of the situation and, as a result, it makes little sense to make sweeping generalizations that "environmental regulations have no impact on competitiveness" on the one hand or that "more stringent regulations will hurt competitiveness." As the MedPolicies case studies show, the impacts of environmental policy changes on exports depend on several clearly identified pieces of information, including: input cost changes due to the regulatory change; the share of the regulated inputs in total costs; profit rates in the sector; supply response and returns to scale in the sector; domestic and export demand elasticities; and possibilities for efficiency improvements. It is the combination of these factors that determine the impact of environmental policy changes on exports.

In sum, environmental policy changes will have smaller impacts on production and exports when policy changes: (i) lead to small cost changes; (ii) affect inputs that are a small portion of overall costs; (iii) affect sectors with limited supply response; and (iv) affect sectors that have relatively less elastic export demands in terms of own price. Impacts of new policy changes on exports will be larger when the opposite is true.
For all country case studies, much of the needed information on supply and demand elasticities (with respect to output price) for various sectors are essentially missing. This lack of understanding of the basic workings of these economies is symptomatic of the lack of data and resources and perhaps interest in the creation of such information. Even for potatoes in Cyprus, which are the key agricultural export for the country, information on such elasticities are absent. Fortunately, while precise estimates may not be available, reasonable initial estimates of all the individual pieces of information for the partial equilibrium approaches used here can be based on common sense, existing information (especially for cost shares and profit rates), and existing estimates in the literature for related sectors or similar sectors in other countries. Sensitivity analysis can then be used to discuss how the estimated impacts change depending on the detailed assumptions used.

While perhaps the most difficult to estimate, the ability to make improvements in the efficiency with which regulated inputs are used will probably be one of the key factors in the future. Where firms are able to innovate and become more efficient in low-cost ways, the impacts of more stringent environmental policies on exports should be minor (and vice versa).

\section{NOTES}

1. The overall MedPolicies Initiative included 13 nonEU countries in the Mediterranean region. MedPolicies supported case studies on three topics (trade and environment, air pollution, and environmental liability and privatization). This paper focuses exclusively on the trade and environment case studies.

2. A more in-depth discussion of the issues can be found in the complete country-specific case studies reported in HIID (2000).

3. By products of phosphoric acid production include various types of air pollution in the evaporation process as well as solid waste known as phosphor gypsum, which contains some levels of radioactivity.

4. See Krutilla (1991), Anderson (1992), Smith and Espinosa (1996) for additional simple graphical overviews of this topic. See Van Beers and Van den Bergh (1996, 1997), Esty and Geradin (1998), Jaffe, Peterson,
Portney, and Stavins (1995) for more complete introductions to the topic.

5. This last term in (2) is directly related to the concept of returns to scale of the production function. Since $Y / X$ is the average product of water in potato production $\left(\mathrm{AP}_{X}\right)$, and since $\partial X^{\mathrm{c}} / \partial y=1 /[\partial f / \partial X]$ is just one divided by the marginal product of water $\left(1 / \mathrm{MP}_{X}\right), \eta_{x y}=\mathrm{AP}_{X} /$ $\mathrm{MP}_{X}$, which must be greater than one with decreasing returns to scale (and equals one with constant returns to scale)

6. To estimate this elasticity, annual production and price data were obtained from government statistics to estimate a simple log-log supply function, in which case the estimated parameter on output price is also the supply elasticity. The details and data used for this estimation are available directly from the Cyprus Case Study Leader. 
7. Eq. (7) is the simple extension of Case 1 assuming no efficiency improvements. To complete the calculations, the percentage change in production and exports can be approximated by multiplying the elasticities in (7) by the policy induced-change input costs.

8. The lack of such information should not be too surprising in many situations. For example, Abler and Shortle (1997, p. 70) conclude the following for elasticity information in agriculture: "In the US, although estimates are more plentiful, there are many large disagree- ments between studies. The bottom line is that EU policymakers are basically operating in the dark, while US policymakers are not too far ahead."

9. Note that the original Turkish case study used a somewhat different modeling approach. For comparison purposes with the other case studies, the basic information for Turkish case study used here is reported in Table 2 , which are used to estimate the impacts reported in Table 3 . The results are essentially the same here as reported in the Turkish study.

\section{REFERENCES}

Abler, D. G., \& Shortle, J. S. (1997). Modeling environmental and trade policy linkages: the case of EU and US agriculture. In W. E. Martin, \& L. A. McDonald (Eds.), Modeling Environmental Policy (pp. 43-76). Norwell, MA: Kluwer Academic Publishers.

Anderson, K. (1992). The standard welfare economics of policies affecting trade and the environment. In $\mathrm{K}$. Anderson, \& R. Blackhurst (Eds.), The Greening of World Trade Issues (pp. 25-48). Ann Arbor, MI: University of Michigan Press.

Armington, P. S. (1969). The geographic pattern of trade and the effects of price changes. IMF Staff Papers, 16(1), 176-199.

Dervis, K., deMelo, J., \& Robinson, S. (1989). General equilibrium models for development policy. Washington, DC: The World Bank (World Bank Paper Back Edition, August, 1989).

Esty, D. C., \& Geradin, D. (1998). Environmental protection and international competitiveness. Journal of World Trade, 32, 5-46.

Harvard Institute for International Development (HIID) (2000). Trade and environment and international competitiveness in the mediterranean region: selected case studies, Cambridge, MA: HIID.

Jaffe, A. B., Peterson, S. R., Portney, P. R., \& Stavins, R. N. (1995). Environmental regulation and the competitiveness of US manufacturing: what does the evidence tell us? Journal of Economic Literature, 33(1), 132-163.

Krutilla, K. (1991). Environmental regulation in an open economy. Journal of Environmental Economics and Management, 20(2), 127-142.

Larson, B. (2000). Evaluating the impact of specific environmental regulations on exports. Land Economics, 76, 534-549.

Porter, M. E. (1990). The competitive advantage of nations. New York: Free Press.

Smith, V. K., \& Espinosa, J. A. (1996). Environmental and trade policies: some methodological lessons. Environment and Development Economics, 1(1), 19-40.

Sullivan, J., Wanio, J., \& Roningen, V. (1989). A database for trade liberalization studies. Washington DC: United States Department of Agriculture, Economic Research Service, Staff Report AGES89-12.
Tobey, J. A. (1990). The effects of domestic environmental policies on patterns of world trade: an empirical test. Kyklos, 43(2), 191-209.

United Nations Economic and Social Commission for Western Asia (1999). Report on the Expert Group Meeting on Environment and Trade Issues: The Impact of WTO Environment Committee Decisions on the ESCWA Member States, November 2-4.

Van Beers, C., \& Van den Bergh, J. C. J. M. (1996). An overview of methodological approaches in the analysis of trade and environment. Journal of World Trade, 30(1), 143-167.

Van Beers, C., \& Van den Bergh, J. C. J. M. (1997). An empirical multi-country analysis of the impact of environmental regulations on foreign trade flows. Kyklos, 50(1), 29-46.

\section{APPENDIX A}

\section{A.1. Adding efficiency improvements to the base model}

To include the possibility that stricter environmental policies induce efficiency improvements in the production process, the following additional notation is needed:

$f(q X, K)$ the technical production function relating inputs to output so that $Y=$ $f(q X, K)$;

$q \quad$ an input efficiency parameter; and

$z=q x$ the "effective" amount of the input used.

With this new form of the production function, the profit function becomes $\pi=\pi(p, w)$ $q, r)$, where the term $w / q$ is the effective price of the regulated input. Using essentially the same process as outlined with the basic model, the final effect of any regulatory change that increases $w$ depends on how this effective input 
price changes. As shown in Larson (2000), the crossprice elasticity for Case 2 (i.e. Case $1+$ efficiency improvements) becomes:

$$
\Psi_{y w}=\left(1-\eta_{q w}\right) \eta_{y w}
$$

which is just the crossprice elasticity from Eq. (3) in the text, and $\eta_{q w}$ shows the percentage increase in the efficiency of input use induced by a change in the price of the input. In general, when environmental policy has a "good" impact on either input quality or incentives to use the input more efficiently, it is possible that $\eta_{q w}$ is positive. If $\eta_{q w}>1$, the expression in (A.1) is positive, which allows for the possibility that more stringent environmental regulations could induce more exports. While $\eta_{q w}$ is a useful conceptual idea, how to calculate or estimate this number is not that clear in most circumstances. As a result, it is probably best to use this idea as a potential effect that can be included in additional sensitivity analyses related to the Case 1 results.

Both efficiency improvements and export price adjustments can be easily included into the analysis simultaneously. The elasticity $\Psi_{y w}$ from Eq. (A.1) can be simply substituted for $\eta_{y w}$ in Eqs. (6) and (7) in the text to include efficiency improvements into this analysis as well.

\section{A.2. The "average cost" case}

It is also possible that environmental regulations cannot be attributed to some specific input or inputs. In such situations, it is possible to evaluate the impact of regulations that increase average production costs by some amount " $m$ " (e.g., $\$ 8$ per unit of output). In this case, for example, let $M\left(R^{0}\right)=0$ be the initial regulatory situation and let $M\left(R^{1}\right)=m$ represent the regulatory cost increase due to more stringent regulations. As a result, $\mathrm{d} M=$ $m$, and $m / C$ is the percentage increase in production costs due to the environmental policy. For perspective, Tobey (1990) defines pollution intensive sectors as those sectors with annual pollution abatement costs driven by environmental policies are greater that $1.85 \%$ of total production costs (i.e. where $m / C>0.185$ ).

In such situations such as with end-of-pipe pollution control technologies it may be difficult to attribute environmental regulatory cost changes to specific inputs. In such circumstances, there may be data or information available on how some regulatory change is likely to affect average production costs, in which case the cost function can be written as $C=C(w, r, y)+m y$, where $m$ represents an increase in average production costs due to the regulation. In this case, the supply function shifts from $Y=Y(p, w, r)$ without the regulation to $Y(p-m, w, r)$ with the regulation. For this case, a similar process as followed in Section 2 can be used to show that the percentage change in output is simply:

$\mathrm{d} Y / Y^{0}=-\eta_{Y p} \frac{m Y^{0}}{C} \frac{1}{1+\theta}$

In this average cost increase case, it is just necessary to know the basic supply elasticity, the percentage increase in costs due to the regulation, and an estimate of the existing production cost increase $(m)$ due to the environmental policy change. Given this change in output, the change in exports can be calculated directly as above. For reference, the base information used in the Turkey case study is: $\eta_{Y p}=0.15, m Y / C=0.06, C / p Y=0.58, E / Y=$ $0.80, \eta_{B p}=-1.00$, and $\eta_{D p}=-6.00$. 